\title{
Challenges faced by China compared with the US in developing wind power
}

\section{Citation}

Lu, Xi, Michael B. McElroy, Wei Peng, Shiyang Liu, Chris P. Nielsen, and Haikun Wang. 2016. "Challenges Faced by China Compared with the US in Developing Wind Power." Nat. Energy 1 (6) (May 23): 16061. doi:10.1038/nenergy.2016.61.

\section{Published Version}

10.1038/nenergy.2016.61

\section{Permanent link}

http://nrs.harvard.edu/urn-3:HUL.InstRepos:27738636

\section{Terms of Use}

This article was downloaded from Harvard University's DASH repository, and is made available under the terms and conditions applicable to Other Posted Material, as set forth at http:// nrs.harvard.edu/urn-3:HUL.InstRepos:dash.current.terms-of-use\#LAA

\section{Share Your Story}

The Harvard community has made this article openly available.

Please share how this access benefits you. Submit a story.

Accessibility 


\section{Challenges Faced by China Compared with the US in Developing Wind Power}

Xi Lu ${ }^{1,2, *}$, Michael B. McElroy ${ }^{2,3, *}$, Wei Peng ${ }^{4}$, Shiyang Liu ${ }^{5}$, Chris P. Nielsen ${ }^{2}$, Haikun Wang ${ }^{6}$

\section{Affiliations:}

${ }^{1}$ School of Environment and State Key Joint Laboratory of Environment Simulation and Pollution Control, Tsinghua University, Beijing 10084, P.R. China

${ }^{2}$ Harvard John A. Paulson School of Engineering and Applied Sciences, Harvard University, Cambridge, MA 02138, USA.

${ }^{3}$ Department of Earth and Planetary Sciences, Harvard University, Cambridge, MA, 02138, USA.

${ }^{4}$ Woodrow Wilson School of Public and International Affairs, Princeton University, Princeton, NJ 08544

${ }^{5}$ National School of Development, Peking University, Beijing 100871, P.R. China

${ }^{6}$ State Key Laboratory of Pollution Control and Resource Reuse, School of the Environment, Nanjing University, Nanjing 210023, P.R. China

*Correspondence to: $\underline{\text { mbm@seas.harvard.edu, xilu@tsinghua.edu.cn }}$ 


\section{Abstract}

In the $21^{\text {st }}$ Conference of the Parties held in Paris in December 2015, China pledged to peak its carbon emissions and increase non-fossil energy to $20 \%$ by 2030 or earlier. Expanding renewable capacity, especially wind power, is a central strategy to achieve these climate goals. Despite greater capacity for wind installation in China compared to the US (114.7 vs. $65.9 \mathrm{GW})$, less wind electricity is generated in China (153.4 vs. $181.8 \mathrm{TWh})$. Here, we quantify the relative importance of the key factors accounting for the unsatisfactory performance of Chinese wind farms. Different from qualitative studies, we find that the difference in wind resources explains only a small fraction of the current US-China difference in wind power output (-17.9\% in 2012); the curtailment of wind power, differences in turbine quality and delayed connection to the grid are identified as the three primary factors (respectively $-49.3 \%,-50.2 \%$, and $-50.3 \%$ in 2012). Improvements in both technology choices and the policy environment are critical in addressing these challenges.

\section{** Main text}

China and the US are the top two $\mathrm{CO}_{2}$ emitters in the world, together accounting for $45.6 \%$ of the global total ${ }^{1}$. Carbon mitigation efforts by these two countries are thus critical for curbing global climate change $\mathrm{e}^{2,3}$. In the landmark US-China climate deal announced in November 2014 and the more recently concluded $21^{\text {st }}$ $\begin{array}{llll}\text { Conference of the Parties } & \text { at }\end{array}$ (https://www.whitehouse.gov/the-press-office/2015/09/25/fact-sheet-united-states-and-china-i 
ssue-joint-presidential-statement), China pledged to peak its carbon emissions by 2030 or earlier, and to increase low-carbon energy to $20 \%$ in its total primary energy mix; the US committed to cut its carbon emissions by $26-28 \%$ relative to the 2005 level, following earlier announced long-term target for 2050 to lower its emissions by $83 \%$ relative to 2005 . Among all the low-carbon technology choices, wind power development is a central strategy for both countries to achieve their climate goals.

The US pioneered in the development of wind-powered generation of electricity in the 1980's and early 1990's. It lost its lead to Europe in the late 1990's as cheap oil, coal and gas reduced incentives for US utilities to invest in alternative sources of energy. The US has emerged once again, since the 1990s, as a major player in global wind power development, in part in response to the production tax credit (PTC) incentive introduced in $1992^{4}$. China, in comparison, has experienced a rapid scale-up of wind power capacity since the passage of the Renewable Energy Law in 2005, and has become the world's top wind installer since 2010. The wind installation target set in 2006 for 2020 (30GW) was already exceeded by nearly $400 \%$ by the end of $2015(145.1 \mathrm{GW})^{5,6}$. China currently accounts for $33.6 \%$ of total global installed wind capacity, with US ranking second $(17.2 \%)^{7}$. Despite greater total installed capacity, the actual wind-generated electricity output is in China less than in the US (Figure 1). The unsatisfactory performance of Chinese wind farms not only harms the profitability of existing wind investments, but also reduces the economic attractiveness of future investments. 

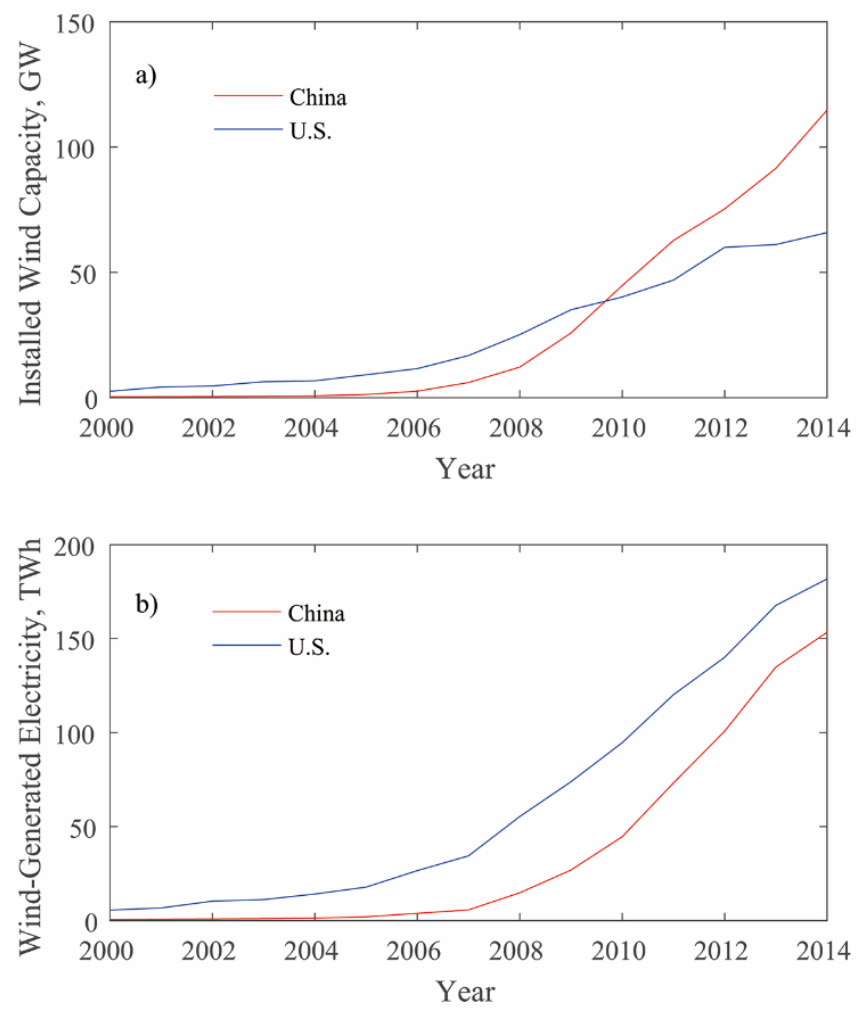

Figure 1 A comparison of wind power deployment for China and the US from 2000 to 2014. a) Installed capacity and b) wind-generated electricity. Data were derived from "Global Wind Statistics 2014" edited by the Global Wind Energy Council (GWEC) ${ }^{5}$.

Based on qualitative methods, previous studies indicated a variety of factors that may contribute to the Chinese shortfall: wind power resources may be intrinsically less favorable in China than in the US ${ }^{8,9}$; the time lag may be longer in China to connect wind farms to the grid $^{10-13}$; the quality of turbines installed in China may be inferior to those installed in the US ${ }^{13-15}$; in addition, for reasons specific for China, wind power curtailment is more pervasive due to an inflexible power generation fleet dominated by coal $^{16-18}$. Yet the relative importance of these contributing factors is methodologically challenging to quantify. Here we propose a method based on a logarithmic-mean-divisia-index (LMDI) approach ${ }^{19}$ to quantify their relative importance, and introduce a new parameter to characterise the overall quality of wind turbines. We find that, although the national total wind resources are less favorable in China 
than in the contiguous US, the available wind resources for the installed wind farms in these two countries are comparable. Our results suggest that curtailment of wind power, differences in turbine quality and delayed connection to the grid are the primary factors accounting for the current US-China difference.

\section{Key Factors Determining Wind Energy Production}

The annual total electricity output from installed wind farms can be calculated as the product of total capacity $(C)$, the fraction of installed capacity connected to the grid $(G)$, the potential capacity factor for wind resources $\left(C F_{\text {est }}\right)$, the virtual turbine quality $(Q)$, the curtailment rate $(\mathrm{Cr})$ and the total hours of year (see equation 2 in Methods). A methodology to evaluate the overall quality of wind turbines that have been installed is missing in existing literature, despite its significance for the design of future wind development strategies. We introduce therefore a parameter $(Q)$ to characterise the overall quality of existing wind turbines, comparing the actual output with the counterfactual performance if GE $2.5 \mathrm{MW}$ turbines were installed instead. $Q$ is a composite factor reflecting primarily turbine quality, but is affected also by the technical limits on the deployment and operation of wind farms.

We use the LMDI decomposition approach to quantify the relative contributions of these factors, in order to explain the discrepancy in wind power output in China as compared to the US for the year of 2012. As illustrated in Figure 2, on the one hand the total capacity of wind farms installed in China exceeds that in the US, which should lead to greater wind-generated electricity in China relative to the US (67.7\%); on the other hand, the advantage of greater installed capacity in China is more than offset by the combined effects of delayed 
grid-connection (negative 50.3\%), less favorable wind resources (negative 17.9\%) and lower quality of wind turbines (negative 50.2\%). China's high curtailment rate for wind power (negative $49.3 \%$ ) further reduces the actual wind power generation. In total, wind-generated electricity in China is 39.3 TWh less than that in the US. With other factors fixed, curtailment of wind power in China would contribute to such shortage by 19.37 TWh, the magnitude for which is comparable to the total electricity generated from wind in Canada in $2012^{5}$. A thorough understanding of the differences in the above-mentioned factors requires further discussion in a broader technical and policy context both for China and for the US.

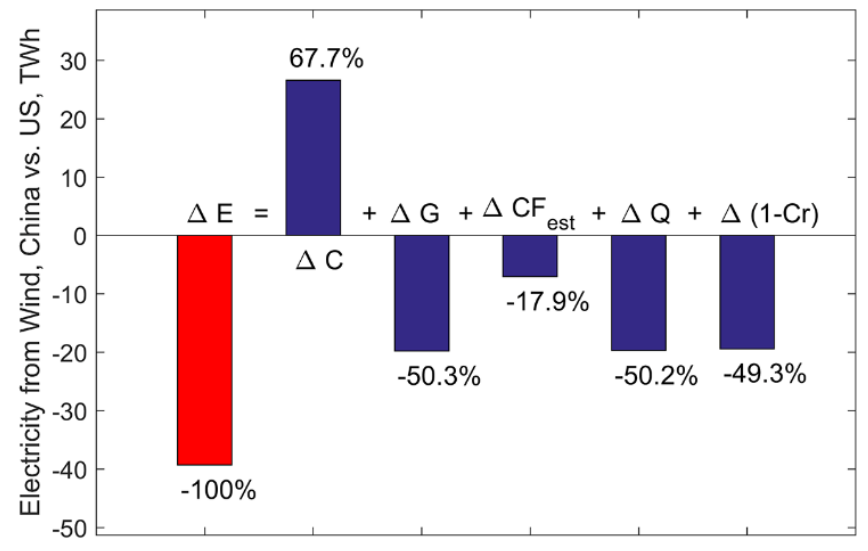

Figure 2 Contribution of different factors in explaining the China-US difference in wind power output. By the scale of the vertical axis, the red bar indicates the total difference of -39.3 TWh of wind-generated electricity in China as compared to the US in 2012, with percentages representing the relative contributions to this difference from the different factors (blue bars). Thus, $50.3 \%, 17.9 \%, 50.2 \%$ and $49.3 \%$ of the lower power output in China is attributed to the differences $(\Delta)$ in $G, C F_{\text {est. }}, Q$, and (1-Cr) respectively. The reduction in output represented by these influences is offset by the positive contribution from the higher value for the installed capacity $(C)$ in China.

\section{Quality of Wind Resources for Existing Wind Farms}

Total wind resources over the contiguous US are notably superior to those in China, Assuming that GE 2.5 MW turbines were deployed in both countries, we find a mean value 
for CF in the U.S of 0.286 , higher than the value of 0.224 for China. The discrepancy reflects the differences in meteorological conditions and topography in the two countries. A significant portion of the wind power potential in China is located in Tibet, where local demand for electricity is low and where the environment is not particularly favorable for deployment of wind turbines. Excluding Tibet, the mean potential value for CF in China would be reduced to 0.217 .

We estimate then the potential CF for the actual installation sites in China and US, assuming deployment of GE 2.5 MW turbines. Figure 3 demonstrates the geographical distribution of potential capacity factors $\left(C F_{\text {est }}\right)$ evaluated for wind resources (a) for China and (b) for the contiguous US. In fact, the mean values for potential CF for the current geographic sites are comparable for both China (0.319) and the US (0.344). This implies that regions with good wind resources have been preferentially selected for deployment in China, notably in the northern and northeastern regions (Figure 3). 


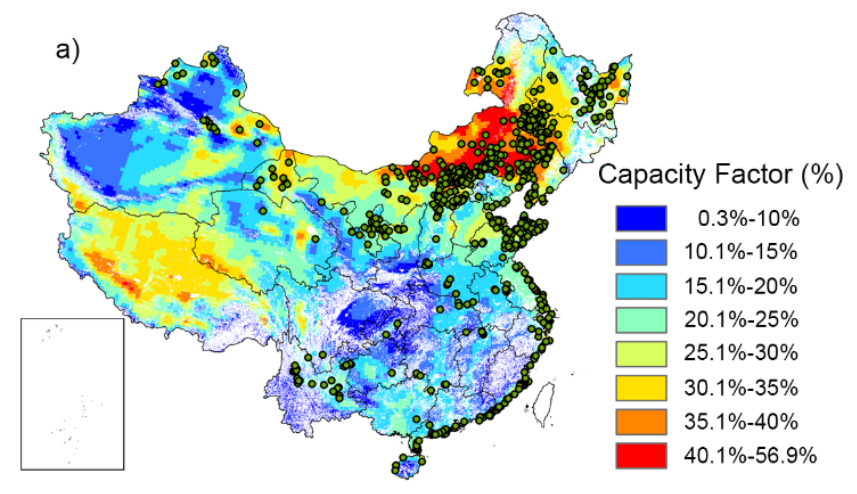

Mean values of $\mathrm{CF}$ :

China mainland without Tibet, 0.217; Existing wind sites, 0.319

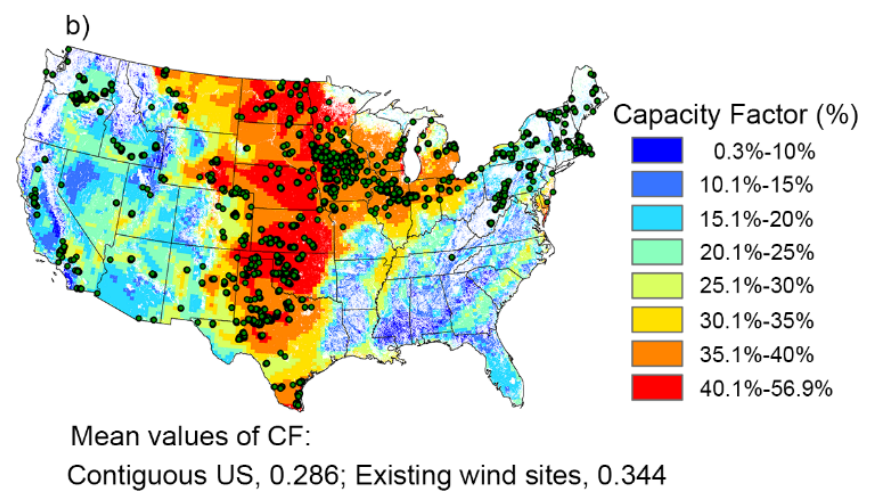

Figure 3 Geographical distribution of capacity factors ( $\mathrm{CFs}$ ) evaluated for wind resources assuming deployment of a network of GE 2.5 MW turbines. a) Distribution of CFs for China and $b$ ) for the contiguous US. The green dots indicate the locations of existing wind farms for the two countries at the end of 2012. A mean value of potential CF is evaluated as 0.286 for the contiguous US in comparison to 0.217 for China mainland excluding the Tibet region. Mean values of potential CF for the exiting wind farms are respectively 0.344 in the US and 0.319 in China. The wind data adopted for evaluation of CFs were derived from the Goddard Earth Observing System Data Assimilation System (GEOS-5) for 2009 by the US National Aeronautics and Space Administration (NASA) ${ }^{20}$. The location information for wind farms in China were derived from a special report on existing wind projects in $\mathrm{China}^{21}$ and for the US derived from a database from American Wind Energy Association (AWEA) (http://www.awea.org/Resources/Content.aspx?ItemNumber=5841\&navItemNumber=5845).

\section{Size and Quality of Installed Wind Turbines}

China was a late entrant to the wind industry and made its debut mainly with less efficient, smaller turbines. As illustrated in Figure 4, the average nameplate capacity for newly added wind farms in China was less than $1 \mathrm{MW}$ up to $2007^{12}$. While China is catching 
up rapidly in installing large-size wind turbines, it still lags the US in terms of turbine size even for the most recently installed wind farms. Operational wind turbines with a nameplate capacity greater than $2 \mathrm{MW}$ accounted for only $2.7 \%$ of total installed wind capacity in China, in contrast to $31.9 \%$ for the US in 2012 . The national average CF from 2008 to 2013 in the US is 0.314 for all wind installations, significantly higher than the average CF for wind farms in China of 0.227 (see Supplementary Table 1) ${ }^{22}$. Even including curtailed wind power, the average value for the CF of wind farms in China was still 20\% lower than for the US. This difference may be attributable to a variety of factors: most importantly lower quality and reliability of wind turbines in China, as well as micro-siting and operational shortcomings.

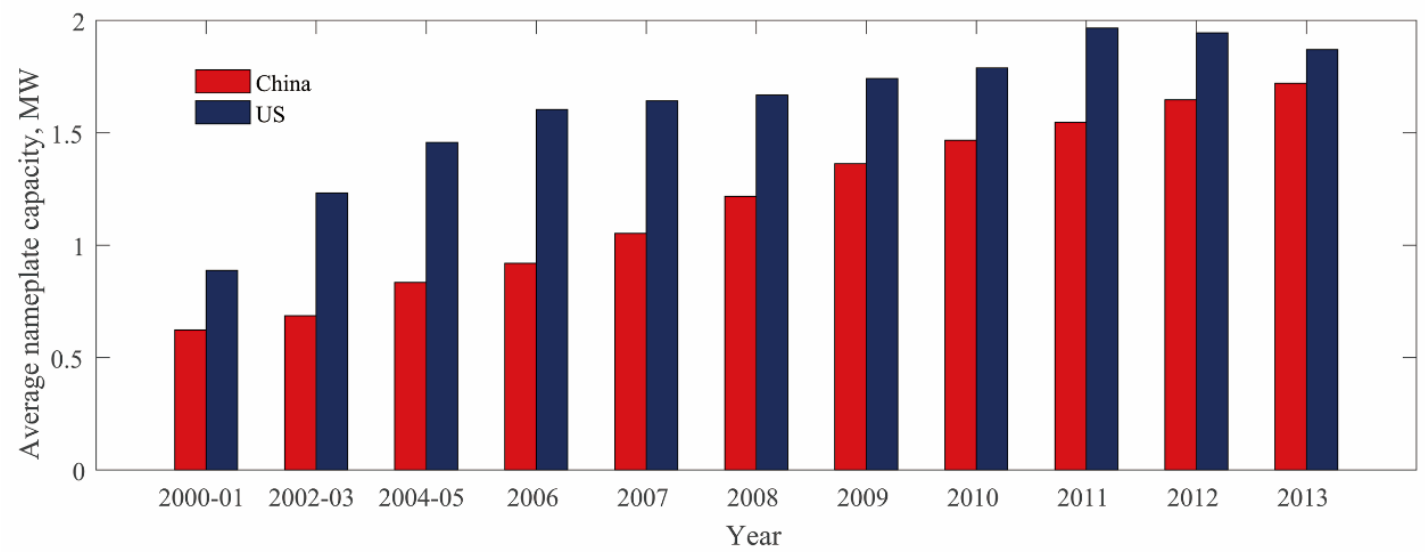

Figure 4 Average nameplate capacity for turbines installed in China and the US from 2000 to 2013. Data for Chinese wind turbines were derived from China Wind Energy Outlook ${ }^{12}$ and for the US wind turbines derived from 2013 Wind Technologies Market Report ${ }^{23}$. Only turbines larger than $100 \mathrm{~kW}$ are included.

In part due to the local-component requirement policy that prevailed in China until 2009, the majority of wind turbines installed in China by the end of 2012 were domestically produced, with only $13.7 \%$ of the total installed turbines supplied by international manufacturers. For the $13.0 \mathrm{GW}$ of wind capacity added in 2012 , approximately $92.5 \%$ was domestically sourced, with only $7.5 \%$ supplied by international manufacturers (Gamesa, 
Vestas and GE) $)^{12}$. While domestic manufacturers have made progress in producing large wind turbines $(>2 \mathrm{MW})$ in recent years, technology catch-up remains challenging for core technologies including integrated design, load optimization, optimization for control strategy and grid-connection performance, which results in an uneven quality for some of the domestically produced turbines ${ }^{12-15,24}$. Increasing the years of operation for existing wind farms in China also highlighted a variety of problems starting from the second half of 2009 including incidences of tower collapses, blade ruptures, and nacelle fires ${ }^{12}$. As a result, the virtual turbine quality value of $Q$ was evaluated at 0.782 on average for Chinese wind farms in 2012, significantly lower than the value inferred for the US, 0.935 .

\section{Delayed Grid Connection in China}

A significant fraction of newly installed wind turbines in China were not yet grid-connected, hence unable to produce electricity. The problem was particularly serious between 2006 and 2010 (see the Supplementary Figure 1). With double-digit annual growth rates over this time frame, wind capacity expansion significantly outpaced grid connection and integration capability in northern China. Idle capacity in 2010 reached $15.2 \mathrm{GW}$, as much as $33.9 \%$ of the total installed capacity ${ }^{12}$.

Part of the problem was rooted in the wind approval process. As wind farms smaller than 50 MW could be approved directly by provincial governments before 2011, a large number of 49.5 MW wind farms were approved by local government, without coordination with grid expansion planning. Realizing the grid-connection bottleneck, the National Energy Administration took back the approval right for small wind projects in 2011. An agreement 
between wind farm developers and grid companies is currently a prerequisite for approval of wind projects. As a result, idled capacity declined to $15.7 \%$ in 2013. In 2015, a new policy was introduced, which withholds permits for construction of new wind farms in regions where the curtailment ratio of existing wind farms exceeds $20 \%{ }^{25}$.

\section{High Curtailment Rate of Wind Power in China}

On a national scale, approximately $17.2 \%$ and $10.7 \%$ of the total wind power in China was curtailed in 2012 and 2013 respectively, resulting in annual financial losses of more than one billion US dollars ${ }^{26}$. The situation is particularly serious in the three north regions, where more than $86.4 \%$ of the national total capacity for wind power is deployed. With inadequate transmission capacity to allow power balancing at greater geographic scale, the local generation fleet has to adjust its output in order to accommodate variable and intermittent wind power generation. However, coal-fired power plants, as the dominant generation source in China's power system, are inflexible in adjusting their output. A conventional coal-fired power plant can operate only at power outputs above $50 \%$ of its nameplate capacity and it takes multiple hours for a plant to recover from a cold $\mathrm{start}^{27}$. In contrast, approximately $47 \%$ of the US electricity is produced by gas-fired systems and other flexible generating units, which contribute to the much lower curtailment rate experienced in the US $(2.6 \% \text { in } 2012)^{23}$.

The situation in northern China during winter is exacerbated further by incompatible policies promoting wind development on the one hand, while prioritising coal-fired combined heat and power (CHP) generation on the other hand (Supplementary Figure 2). CHP has been widely perceived as an effective means to improve the efficiency of energy systems, since it 
converts the energy of fuels to a combination of electricity and heat with a combined efficiency of up to $80 \%{ }^{28}$, more than doubling the efficiency for electricity generation from a conventional coal-fired power plant (approximately 33\%). The nationwide capacities of CHP increased from $69.8 \mathrm{GW}$ in 2005 to $251.8 \mathrm{GW}$ in 2013 , a growth rate significantly higher than that for conventional coal-fired power plants (Supplementary Notes 2, and Supplementary Figures 5 and 6). The share of CHP in the power systems of the three north regions rose from $25 \%$ in 2005 to $44.7 \%$ in $2013^{29}$. However, as CHP plants are obliged to operate at essentially full capacity in winter in order to meet the demand for hot water ${ }^{17}$, their presence not only lowers the residual load for wind, but reduces also the flexibility of the thermal generation fleet to accommodate to the variable wind output. As a consequence, significant wind curtailment occurs exactly when the potential wind output would otherwise be greatest (wind conditions are most favorable in winter). The issue of curtailment is most serious in Inner Mongolia and Jilin, where approximately $42.1 \%$ and $76.9 \%$ of the coal-fired power plants involve $\mathrm{CHP}^{29}$ (see Supplementary Notes 1 and Supplementary Figure 4).

\section{Conclusions and Policy Implications}

Our analysis indicates that the unsatisfactory performance of Chinese wind farms compared to those in the US can be explained mainly by differences in three factors: virtual turbine quality, curtailment, and delayed grid connection. The lower virtual turbine quality can be addressed mainly within the wind manufacturing and supply chain. In the short-term, opening up the domestic market to international suppliers could improve the quality of installed turbines. In the long-term, enhancing indigenous innovation capacity through 
domestic R\&D efforts and technology transfer agreements will accelerate technological progress and improve the quality of domestically produced turbines. In fact, China's wind turbine technology has been catching up quickly with international technological frontiers in the past decade, owing to a variety of favorable government policies ${ }^{30}$. With the evolving maturity of the wind power market, the virtual quality of wind turbines in China is expected to transition in short order to mirror the international advanced level.

Reducing wind curtailment and accelerating grid connection, in comparison, requires reform efforts in China's electric power system to make both the generation and transmission systems more renewable-friendly. Here we provide recommendations from three perspectives: increasing the flexibility of the power generation system; coordinating generation and transmission planning; and introducing a renewable-friendly dispatch order (Supplementary Figure 3).

First of all, proven technological options can be used to increase the flexibility of the power generation system to accommodate variable and intermittent renewable output. To increase the flexibility of CHP, recent regulation ${ }^{31}$ in China encourages hot water supplied by CHP systems to be complemented with electrified boilers. The overall efficiency of the system could be enhanced by incorporating hot water storage tanks in CHP facilities or by adding storage capacity to buildings supplied with this hot water. Furthermore, future improvement in wind power prediction can also benefit the planning and dispatch decisions to favor wind integration. Another option is to utilise excessive wind power to produce a secondary energy carrier. For example, $\mathrm{H}_{2}$ produced by electrolysis, which could then be 
combined with $\mathrm{CO}_{2}$ captured from local coal-fired plants to produce a liquid fuel such as methanol. Last but not least, a number of electricity storage technologies are available to store excessive wind power and reduce curtailment. For instance, pumped hydro storage (PHS) facilities could provide an opportunity to store electricity when supply exceeds demand. Current PHS capacity in China amounts to $16.9 \mathrm{GW}$, and is projected to increase to $50 \mathrm{GW}$ by $2020^{32}$. Much of this additional capacity is planned for the eastern and southern regions of the country, with only $16 \mathrm{GW}$ for the north. Increasing the development of PHS in the north could make an important contribution to limiting wind curtailment. Besides PHS, advances in battery technology, for example the flow design described by Huskinson et $\mathrm{al}^{33}$, could provide important opportunities for storage of wind-generated electricity. Batteries incorporated in electric vehicles (EVs) could also provide an additional opportunity for power storage. In China's New Energy Automobile Development Plan released in 2012, the stock of EVs (including plug-in, pure electric and hydrogen-fueled vehicles) was targeted at five million by 2020, expected to grow significantly by $2030^{34}$.

Secondly, strategic and coordinated generation deployment and transmission investment can address grid-connection delay and the geographic mismatch between renewable resources and demand centers. While proactive transmission planning has been actively discussed and explored in the US in order to connect renewable capacity in remote areas to demand centers ${ }^{35}$, generation planning and transmission planning involve distinct processes in China, with problems respectively that exacerbate the wind integration bottleneck. The generation fleet in the wind-abundant three north regions has limited flexibility to accommodate to variable wind power due to prioritised dispatch of CHP plants for heating over winter. The addition of 
base-load nuclear capacity currently underway in the northeast region potentially poses additional challenges ${ }^{16}$. Meanwhile, the transmission capacity is inadequate in comparison to the fast scale-up of wind capacity, which constrains the option of exporting excess wind-generated electricity for consumption elsewhere. The grid bottleneck has been alleviated recently as the air pollution crisis in China has already led to an expansion in west-to-east long-distance transmission to reduce eastern coal power production and resulting air pollution. One operating and a few planned ultra-high voltage transmission (UHV) lines already experiment with the strategy for transmitting combined wind power and coal power from western wind bases to eastern population centers (http://www.nea.gov.cn/2014-01/28/c_133080014.htm). In addition, encouraging wind development in eastern low-wind-speed regions can be a cost-effective option when the avoided transmission costs and curtailment losses outweigh the higher wind production costs.

Thirdly, renewable-friendly dispatch will benefit wind power integration. China has long employed a production quota system that guarantees a minimum number of hours per year for the operation of thermal power plants. This equal-share dispatch system leads to a predetermined level of thermal output, with limited ability to adjust and accommodate variable renewable output. In contrast, the dispatch decisions in the US are based on marginal production costs, which prioritise the dispatch of renewable electricity due to its lower marginal cost compared with fossil-based units that require fuel inputs. Meanwhile, although the Renewable Energy Law requires grid companies to purchase all the wind power generated by qualified turbines, unless curtailment is absolutely required to maintain grid reliability this mandate, is weakly enforced in practice. This is because it is technologically challenging to 
determine the level of necessary curtailment. The nontransparent real-time electricity dispatch decisions also deepen the information asymmetry between the regulator and grid companies, posing additional difficulty for regulating curtailment. In the recently announced US-China Joint Presidential Statement on Climate (https://www.whitehouse.gov/the-press-office/2015/09/25/fact-sheet-united-states-and-china-i ssue-joint-presidential-statement), China committed to promote a green power dispatch protocol that will prioritise renewable power generation in distribution and dispatch decisions. Despite the potential institutional challenges, implementing green dispatch can make China's grid system renewables-friendly, benefiting thus wind power integration.

In a broader context, the significant performance difference between the wind capacity installed in China and in the US also warrants increased attention to the regional disparities in real-world renewable deployment costs. To assess global emission mitigation pathways, large-scale energy economic models traditionally assume a uniform cost for technology across countries $^{3}$. Recent literature has explored the significance of cross-country variations in technology costs that may affect climate mitigation strategies. For instance, considering country-specific investment risks under various institutional environments can lead to different temporal and spatial patterns for carbon mitigation efforts ${ }^{36}$. Our analysis therefore lays an empirical foundation for introducing such region-specific renewable technology costs into global integrated assessment models.

\section{Methods}


LMDI Analysis. The LMDI model is a tool for index decomposition analysis, which has been widely applied in the analyses of energy demand and supply, carbon dioxide emissions, and efficiencies in energy related studies ${ }^{19,37}$. Here, we adopt this method to separate the influences of the different factors on the overall difference in performance of wind farms between China and the US. The annual wind-generated electricity $(E)$ can be calculated as follows:

$$
\begin{aligned}
E & =C_{o p} \cdot C F \cdot(1-C r) \cdot 8760 \\
& =[C \cdot G] \cdot\left[C F_{\text {est }} \cdot Q\right] \cdot(1-C r) \cdot 8760
\end{aligned}
$$

Here, $\mathrm{C}_{\mathrm{OP}}$ refers to grid-connected wind capacity, which can be expressed as the product of total capacity $(C)$ and the fraction of installed capacity connected to the grid (i.e. $C_{O P}=C \cdot G$ ). $\mathrm{CF}$ is the capacity factor that wind farms could realise without curtailment. $\mathrm{Cr}$ is the fraction of wind-generated electricity that is curtailed; and 8760 is the total number of hours in a year.

As the capacity factor realised is location-dependent and affected by issues related to grid operations, teasing out the effect of turbine quality is methodologically difficult. Here, we introduce a new parameter $(Q)$ to characterise the virtual quality of existing wind turbines, comparing the actual performance with the counterfactual performance if GE 2.5 MW turbines were installed. Specifically, we evaluate the potential $\mathrm{CF}\left(C F_{\text {est }}\right)$ that would have been realised if GE 2.5 turbines were installed at the same locations as the existing turbines in China and the US. Adopting $C F_{\text {est }}$ as a benchmark, a parameter $Q$ is defined then as the ratio of $C F$ to $C F_{\text {est }}\left(Q=C F / C F_{\text {est }}\right)$. Equation (1) is expanded accordingly to equation (2).

The actual capacity factor realised in existing wind farms $\left(C F_{\text {real }}\right)$ in China and the US can be expressed using the last three factors $\left(\mathrm{CF}_{\text {est }}, Q\right.$ and $\left.\mathrm{Cr}\right)$ in equation (4). 


$$
\begin{aligned}
C F_{\text {real }} & =C F \cdot(1-C r) \\
& =C F_{\text {est }} \cdot Q \cdot(1-C r)
\end{aligned}
$$

The choice of values for $C F_{\text {real }}$ and $C r$ is based on data reported by Chinese and US authorities ${ }^{5,12,22,23}$. Parameter $C F_{\text {est }}$ is calculated using the method by $\mathrm{Lu}$ et $\mathrm{al}^{38,39}$ (see Supplementary Methods). The relationship in equation (4) then allows for a calculation of $Q$, a parameter intended to quantify the overall quality of wind turbines relative to the GE 2.5 MW turbines that are assumed as standard module in this study. Values for all the parameters in equations (1) and (2) for 2012 are summarised in Supplementary Table 2.

The difference in wind-generated electricity between China and the US $(\Delta E)$ is expressed in the additive form of the LMDI decomposition analysis ${ }^{19}$ as a sum of impacts from the individual influential factors as follows:

$$
\Delta E=\Delta E^{C}+\Delta E^{G}+\Delta E^{C F_{\text {est }}}+\Delta E^{Q}+\Delta E^{(1-C r)}
$$

The relative contribution of each factor is evaluated separately using the following relations:

$$
\begin{aligned}
& \Delta E^{C}=\frac{\log \left(C_{C N}\right)-\log \left(C_{U S}\right)}{\log \left(E_{C N}\right)-\log \left(E_{U S}\right)}\left(E_{C N}-E_{U S}\right) \\
& \Delta E^{G}=\frac{\log \left(G_{C N}\right)-\log \left(G_{U S}\right)}{\log \left(E_{C N}\right)-\log \left(E_{U S}\right)}\left(E_{C N}-E_{U S}\right) \\
& \Delta E^{C \text { CFst }}=\frac{\log \left(C F e s E_{N}\right)-\log \left(C F e s t_{S}\right)}{\log \left(E_{C N}\right)-\log \left(E_{U S}\right)}\left(E_{C N}-E_{U S}\right) \\
& \Delta E^{Q}=\frac{\log \left(Q_{E N}\right)-\log \left(Q_{U S}\right)}{\log \left(E_{C N}\right)-\log \left(E_{U S}\right)}\left(E_{C N}-E_{U S}\right)
\end{aligned}
$$




$$
\Delta E^{(1-c r)}=\frac{\log \left[\left(1-C r_{C N}\right]-\log \left[(1-C r)_{U S}\right]\right.}{\log \left(E_{C N}\right)-\log \left(E_{U S}\right)}\left(E_{C N}-E_{U S}\right)
$$

Uncertainty of LMDI approach. With the logarithmic division approach, the unexplained residual terms may be allocated as the contributions of the individual factors $^{19,40,41}$. If the residual terms are large, this could lead to unavoidable ambiguity in assigning the influence to each specific factors. To test the validity of the LMDI approach adopted in this study, an uncertainty analysis is conducted based on the elasticity approach (see Supplementary Methods). The blue bars in Supplementary Figure 8 illustrate how the residual term is allocated to the individual factors. If the residual term is small, as is the case for this analysis, these two approaches should yield similar results.

Evaluation of wind resources. The potential for wind-generated electricity was evaluated both for China and for the US using a wind database appropriate for 2009 derived from the Goddard Earth Observing System Data Assimilation System (GEOS-5) by the US National Aeronautics and Space Administration ${ }^{20}$, following the methodology introduced by Lu et $\mathrm{al}^{8}$ and McElroy et $\mathrm{al}^{39}$. Hourly power outputs from wind were computed and aggregated to compute annually averaged capacity factors ( $\mathrm{CFs}$ ) using the power curve appropriate for GE 2.5 MW wind turbines. Details of the method are described in the Supplementary methods. 


\section{References}

1 BP. Statistical Review of World Energy 2015. 48 (BP, London, United Kingdom, 2015).

2 Clarke, L. et al. International climate policy architectures: Overview of the EMF 22 International Scenarios. Energy Economics 31, S64-S81 (2009).

3 Clarke, L. et al. in Climate Change 2014: Mitigation of Climate Change, Contribution of Working Group III to the Fifth Assessment Report of the Intergovernmental Panel on Climate Change (eds Ottmar Edenhofer et al.) Ch. 6, 418-491 (Cambridge University Press, 2014).

4 Barradale, M. J. Impact of public policy uncertainty on renewable energy investment: Wind power and the production tax credit. Energy Policy 38, 7698-7709, doi:10.1016/j.enpol.2010.08.021 (2010).

5 GWEC. Global Wind Statistics 2014. 4 (Global Wind Energy Council, Brussels, Belgium, 2015).

6 National Power Planning Research Center. in China Energy News Vol. 14 (Renmin RiBao, Beijing, 2013).

7 GWEC. Global Wind Statistics 2015. 4 (Global Wind Energy Council, Brussels, Belgium, 2016).

8 Lu, X., McElroy, M. B. \& Kiviluoma, J. Global potential for wind-generated electricity. Proc. Natl. Acad. Sci. USA 106, 10933-10938, doi:10.1073/pnas.0904101106 (2009).

9 Zhou, Y. Y., Luckow, P., Smith, S. J. \& Clarke, L. Evaluation of Global Onshore Wind Energy Potential and Generation Costs. Environmental Science \& Technology 46, 7857-7864, doi:10.1021/es204706m (2012).

$10 \mathrm{Yu}, \mathrm{X} . \& \mathrm{Qu}, \mathrm{H}$. Wind power in China-Opportunity goes with challenge. Renew. Sust. Energ. Rev. 14, 2232-2237, doi:10.1016/j.rser.2010.03.038 (2010).

11 Yang, M., Patino-Echeverri, D. \& Yang, F. Wind power generation in China: Understanding the mismatch between capacity and generation. Renewable Energy $\mathbf{4 1}$, 145-151, doi:10.1016/j.renene.2011.10.013 (2012).

12 Li, J. et al. 2013 Annual Review and Outlook on China Wind Power. 66 (Chinese Renewable Energy Industries Association, Glboal Wind Energy Coucil, Beijing, China, 2013).

13 Zhao, Z.-y., Yan, H., Zuo, J., Tian, Y.-x. \& Zillante, G. A critical review of factors affecting the wind power generation industry in China. Renew. Sust. Energ. Rev. 19, 499-508, doi:10.1016/j.rser.2012.11.066 (2013).

14 Han, J. Y., Mol, A. P. J., Lu, Y. L. \& Zhang, L. Onshore wind power development in China: Challenges behind a successful story. Energy Policy 37, 2941-2951, doi:10.1016/j.enpol.2009.03.021 (2009).

15 Wang, Z. Y., Qin, H. Y. \& Lewis, J. I. China's wind power industry: Policy support, technological achievements, and emerging challenges. Energy Policy 51, 80-88, doi:10.1016/j.enpol.2012.06.067 (2012). 
Pei, W. et al. Temporal-spatial analysis and improvement measures of Chinese power system for wind power curtailment problem. Renew. Sust. Energ. Rev. 49, 148-168, doi:10.1016/j.rser.2015.04.106 (2015).

17 Long, H., Xu, R. \& He, J. Incorporating the Variability of Wind Power with Electric Heat Pumps. Energies 4, 1748-1762, doi:10.3390/en4101748 (2011).

18 Chen, X. Y., Lu, X., McElroy, M. B., Nielsen, C. P. \& Kang, C. Q. Synergies of Wind Power and Electrified Space Heating: Case Study for Beijing. Environmental Science \& Technology 48, 2016-2024, doi:10.1021/es405653x (2014).

19 Ang, B. W. The LMDI approach to decomposition analysis: a practical guide. Energy Policy 33, 867-871, doi:10.1016/j.enpol.2003.10.010 (2005).

20 Rienecker, M. M. et al. The GEOS-5 Data Assimilation System-Documentation of Versions 5.0.1, 5.1.0, and 5.2.0., 118 (NASA, Washington, DC, 2007).

21 HuaxiaWIND. Report on Market and Existing Projects of Wind Power in China. 147 (HUAXIAWIND Xuzhou, Jiangsu, 2014).

22 U.S. EIA. Electric Power Monthly with Data for July 2015. 225 (U.S. Energy Information Administration, Washington, DC, 2015) http://www.eia.gov/electricity/monthly/pdf/epm.pdf.

23 Wiser, R. \& Bolinger, M. 2013 Wind Technologies Market Report. 96 (Washington, DC, 2014).

24 Ru, P. et al. Behind the development of technology: The transition of innovation modes in China's wind turbine manufacturing industry. Energy Policy 43, 58-69, doi:10.1016/j.enpol.2011.12.025 (2012).

25 NEA. Notice on Further Improving Management for Wind Energy Development, (China's National Energy Administration, Beijing, China, 2015) http://www.sdpc.gov.cn/dffgwdt/201506/t20150609_695498.html

26 SERC. Regulatory Report on Wind Power Integration in Some Critical Regions in China. 111 (State Electricity Regulatory Commission, Beijing, 2012).

27 Kang, C. et al. Toward a More Environmentally Friendly, Efficient, and Effective Integration of Energy Systems in China. IEEE Power \& Energy Magazine 1, 57-64, doi:10.1109/MPE.2013.2268752 (2013).

28 Masters, G. M. Renewable and Efficient Electric Power Systems. 654 (A John Wiley \& Sons, Inc., 2004).

29 Electric Power Statistical Year Book Editorial Board. in China Electric Power Yearbook (China Electric Power Press, Beijing, China, 2006-2014).

30 Lefevre-Marton, N. Catching Up: the Rise of the Chinese Wind Turbine Industry PhD thesis, Princeton University, (2013).

31 NEA. Notice on Enhancing Accommodation of Renewable Power in Three-North Regions. (National Energy Administration, China, Beijing, China, 2016) http://zfxxgk.nea.gov.cn/auto92/201602/t20160216_2202.htm

32 Zeng, M., Zhang, K. \& Liu, D. X. Overall review of pumped-hydro energy storage in China: Status quo, operation mechanism and policy barriers. Renew. Sust. Energ. Rev. 17, 35-43, doi:10.1016/j.rser.2012.05.024 (2013).

33 Huskinson, B. et al. A metal-free organic-inorganic aqueous flow battery. Nature 505, 195-+, doi:10.1038/nature12909 (2014). 
34 Cheung, K. Integration of Renewables Status and challenges in China. 34 (International Energy Agency, Paris, France, 2011).

35 Madrigal, M. \& Stoft, S. Transmission Expansion for Renewable Energy Scale-Up: Emerging Lessons and Recommendations. 170 (The World Bank, Washington, D.C., 2012).

36 Iyer, G. C. et al. Improved representation of investment decisions in assessments of CO2 mitigation. Nature Climate Change 5, 436-440, doi:10.1038/nclimate2553 (2015).

37 Wang, C., Chen, J. N. \& Zou, J. Decomposition of energy-related CO2 emission in China: 1957-2000. Energy 30, 73-83, doi:10.1016/j.energy.2004.04.002 (2005).

38 Lu, X., McElroy, M. B., Nielsen, C. P., Chen, X. \& Huang, J. Optimal integration of offshore wind power for a steadier, environmentally friendlier, supply of electricity in China. Energy Policy 62, 131-138 (2013).

39 McElroy, M. B., Lu, X., Nielsen, C. P. \& Wang, Y. Potential for Wind-Generated Electricity in China. Science 325, 1378-1380, doi:10.1126/science.1175706 (2009).

40 Ang, B. W. \& Liu, N. Negative-value problems of the logarithmic mean Divisia index decomposition approach. Energy Policy 35, 739-742, doi:10.1016/j.enpol.2005.12.004 (2007).

41 Wood, R. \& Lenzen, M. Zero-value problems of the logarithmic mean divisia index decomposition method. Energy Policy 34, 1326-1331, doi:10.1016/j.enpol.2004.11.010 (2006).

\section{Acknowledgements}

The research was supported by the State Environmental Protection Key Laboratory of Sources and Control of Air Pollution Complex, Collaborative Innovation Centre for Regional Environmental Quality, MEP's Special Funds for Research on Public Welfare (201409002), and, and the Volvo Group in a research project of the Research Center for Green Economy and Sustainable Development, Tsinghua University. It was also supported by the Harvard Climate Change Solutions Fund and the Harvard Global Institute.

\section{Author contributions}

X. L. and M.B.M. conceived the idea. X. L. conducted the analysis. X.L. and S-Y. L. collected the data. X.L., M.B.M. and W.P. co-wrote the paper. All authors discussed the results and commented on the manuscript.

\section{Additional information}

Supplementary information is available online. Reprints and permissions information is available online at www.nature.com/reprints. Correspondence and requests for materials should be addressed to X.L. and M.B.M.

\section{Competing interests}

The authors declare no competing financial interests. 